\title{
Research on Legislative Work of Chinese New Authorized Local People's Congress
}

\author{
Chunlei Yang, Lei Huang \\ School of Law, Yangtze University, Jingzhou 434023, China \\ ycl114@sina.com
}

\begin{abstract}
Local legislation is an indispensable important link in the complete system. The characteristics of the legislative work in cities divided into districts should be grasped to help the legislative work. The project determination mechanism need to be improved and the project demonstration should be enhanced to improve the quality of legislation and further promote the rule of law.
\end{abstract}

Keywords: New authorization, the local People's Congress, the legislative work

\section{INTRODUCTION}

The breakthrough of the modification of "the Legislation Law of the People's Republic of China" (the "Legislation Law") in 2015 is the "expansion" of the local legislative power. The rulemaking authority on local regulations is decentralized to all cities divided into districts, extending them from the existing 49 to 282 . This is a major adjustment to the current legislation system of our country, also the modification of the most constitutional significance in this revision process. Whether the reform or the development, the demand for local legislative power is not limited to the national identity of the size or function of a city, but depends on the local economic and social development and the trend and realistic bottleneck of the rule of law and the scientification in local governance. From the standpoint of the balanced development between regions, the elimination of regional differences and bridging the gap between urban and rural areas, the delegation of local legislative power to cities divided into districts is a meaningful initiative to help break through the bottleneck restricting the development of local and the response to the request of the modernization of national governance systems and governance capacity.

\section{The Characteristics of the Legislative Work in Cities Divided into Districts}

\subsection{The Limitations of Authorization}

Cities divided into districts can make local laws and regulations only on three aspects that "urban and rural construction and management, environmental protection and historical and cultural protection", which supposed to be neither absence nor offside nor malposition. Making good use of the local legislative power in the existing legislative matters to achieve the expected economic and social benefits is the foundation and premise of the state to gradually expand the legislative authority of cities divided into districts.

\subsection{The Pertinence of Content}

Cities divided into districts just legislate on provisions that are not clear or specific in laws, regulations and administrative rules. Its main purpose is to fill up the vacancy, rather than that if there is a higher level law we must develop regulations and detailed rules in the city to form a structure between upper laws and lower laws. 


\subsection{The Differences of Regions}

Different regions have their own unique characteristics in the aspects of urban planning, environmental resources and historical culture. Local regulations adapting to local circumstances are needed. Therefore, local legislation must reflect the differences between here and another place, instead of being a sameness and rote. It should get the legal basis for the appropriate local governance based on field investigation and scientific analysis.

\subsection{The Normativity of Formulation}

The authority and seriousness of the legislative work is inseparable from the normative system design. This requires the timely establishment of statutory bodies around the Local People's Congress, the selection of outstanding representative and personnel to carry out legislative preparations and the appearance of regulations on the standardization of legislative activities and procedures to ensure that the new authorized local legislative work can get a good start.

\subsection{The Scientificalness of Operation}

The legislative process needs to meet the standards of science, democracy and openness. It is necessary for regions to form legislative expert advisory bodies and to establish special local legislation research institutions as soon as possible. And making the local legislation easier to understand and operate by soliciting public comment and absorbing professional advice.

\subsection{Outstanding Practicality}

Practice is the sole criterion for testing truth. Law is the efficient instrument to run a country. The life of laws and regulations is to implement. The social adaptability, perspectiveness and stability of law are the main measure of the level of legislation. The important standard to evaluate the pros and cons of a local legislation is the actual results on improving social governance and servicing people's livelihood, which is easy to use, practical and effective.

\section{To ImProve the Project Determination Mechanism to Ensure the Quality of LEGISLATION}

Currently, the urgent task in front of the new authorized local people's Congress is how to establish and improve their own work mechanism and upgrade the level of legislation through absorbing legislative experience and lessons from those local people's Congress that has long acquired the legislative power, constantly adapt to the new changes in the situation of reform, respond to new expectations of local people and enrich and perfect the legal system to get a better playing of the important role of the legal system in promoting scientific development and social harmony and safeguarding the people's rights and benefits.

\subsection{To Give Full Play to the Leading Role of the Local People's Congress and its Standing Committee in the Legislative Work}

Local people's congress and its standing committees, as a local authority and decision-making organ, have the right to compile the legislation programming and planning. In practice, however, the government's activities are more active, while the National People's Congress appears relatively detached because it is not specifically in charge of the management of social affairs. And the relationship between the government and the NPC in the local legislation is often misunderstood as a kind of decentralization, which is not consistent with the basic spirit of our constitution and the principle of the construction of the state power. Although the government has a certain authority to make local regulations, the effectiveness of local regulations is lower than that of local laws and regulations, and most of them are executive regulations. The NPC, as organ of authority, needs to play 
a global leading role on legislation planning and the compilation and arrangement of the legislative program macroscopically. And the law working committee is specifically responsible for the formulation and preparation of legislative planning and programming. Therefore, it is necessary to give full play to the leading role of the NPC and its Standing Committee in the project determination of legislation. First of all, a certain system of legislative project determination should be established to straighten out all aspects of the work process. Such as, the standing committee of Shanghai Congress passed the "Measures for the trial implementation of the project demonstration on legislation project" in 2009. And it had got outstanding achievements in aspect of the application, the content of the argument and the project establishment of the project demonstration, since it was carried out. Secondly, to timely and accurate grasp of the overall situation of reform and development. Channels for the collection of legislative demand information should be established. For the legislative demand information and projects declared by relevant departments, periodic collation and analysis is needed. Meanwhile, we should listen to the report of the relevant departments, and take the initiative to investigate and survey if it is necessary for the problem which is difficult to grasp in the report to directly listen to the views of representatives of different interests and master first-hand information. We should have a general and macro grasp of the significant problems involved in the declared projects before the investigation and research, and further sort out the problem needed to be demonstrated by researching to be targeted to enhance the pertinence and effectiveness of the research and have a clear understanding of the basic situation and main problems of the social relations involved in the research project. On the basis of the correct understanding of the purpose and objective of the legislation, we can discuss or even argue about different opinions during the research to promote the in-depth understanding of the problem and achieve the desired objectives of the survey. Subsequently, to conduct a further thorough argument on the necessity and feasibility of legislation with the authorities based on research findings. For the problems with strong social repercussions or great controversy, the mode of joint argument or hearing should be tried to use to make the different views expressed more directly and adequately. Opinions can be considered to be included in the legislation plan when we reach agreement. Moreover, the coordinating role of the law work committee should be given full play. As the specific legal working institutions of the NPC Standing Committee, the law work committee should take an active part in the discussion in project research and dispatch officials to audit even offer a personal opinion when the special committees and government offices check their own legislative proposals, thus we can have a more objective and comprehensive understanding when drafting legislative plans or programmings at later time.

\subsection{To Broaden the Channels of Project Sources to Promote the Scientization and Democratization of Legislation}

In the process of setting up a project of local laws and regulations, it is necessary to benefit by mutual discussion and broaden the channels to listen to legislative proposals actively to promote the scientization and democratization of legislation. It is recommended to mobilize the enthusiasm of all parties to involve in local legislation from the following aspects.

\subsubsection{Local People's Congresses and Their Standing Committees are the Main Body of Local Legislation}

The Standing Committee of the National People's Congress should exert their enthusiasm and initiative in the work of local legislation or frequently irregularly assign staff to go to the basic level to take the initiative to observe public opinion and ask for information, rather than to wait for the legislative suggestions put forward proactively by other body who has the right of proposal, while it do a good job in the macro work of legislative planning. And it must remain neutral and not be subject 
to departmental interests to put forward legislative suggestion or proposal in a timely and objective manner, submit preliminary examination opinions on relevant legislative suggestions and consider whether to list in the legislative plan.

\subsubsection{To Play the Role of the NPC Deputies in the Project Determination of Local Legislation}

Our deputies are mostly part-time workers from all walks of life. We have more direct contact, close attention and profound understanding to social development and sensitive societal issues related to the livelihood, so we are most possible to put forward good legislative suggestions from a practical point of view. However, due to the lack of awareness and ability of representatives and the relative lack of professional knowledge of law, deputies have not given full play to their initiative. The role of the NPC deputies in the project determination of local legislation should be paid high attention. The electoral system of the deputy and the supervision system should be strict. Deputies' sense of responsibility and participation need to be effectively improved. At the same time, the representative proposal system should be strengthened and perfected to ensure the proposals proposed by representatives get the feedback in time and make the procedure of proposal work have rules to follow.

\subsubsection{The Government and its Departments Continue to Play a Role in the Project Determination of Local Legislation}

The hysteresis quality of law determines that it can not respond to the rapidly changing social development in a timely manner. Since the government and its subordinate functional departments shoulder the function of direct management of the social and economic life in socio-economic life, their understanding of the new problems and contradiction emerging in the society is more timely and comprehensive. And we can master new information, grasp the new trends in time and put forward more scientific and objective legislative proposals. This is the advantage of the government to just make up for the hysteresis quality of law. So it should continue to give full play to its initiative while avoid the limitation of the government's departmental interests. And the working system on the screening and selection of its proposal project should be enhanced and perfected.

\subsubsection{The CPPCC Play a Role in the Project Determination of Legislation}

The people's Political Consultative Conference which has played a significant historical role is the most extensive patriotic democratic united front organization. It has a very wide range of social contact and represents the interests of all aspects of society, which makes it possible to mobilize its enthusiasm and initiative to get all the forces of society come alive and provides advice on local legislative work.

\subsubsection{Experts and Scholars Play an Important Role}

Legislation is a highly professional work which needs the participation of experts and scholars with rich legal professional knowledge and practical experience. In recent years, some regions recruit experts and scholars to provide intellectual support through the form of setting up the legislative expert database, the advisory council on legislative matters, the legislation research center and the legislation assistant system, and we achieved good effect. For example, Henan Provincial People's Congress Standing Committee has improved the expert consulting system, and experts and professors of Henan Academy of Social Sciences, Zhengzhou University and other organizations have made many valuable recommendations on the review and demonstration of the project determination. On the academic front, experts and scholars can play an instructive role in improving the legal quality of the legislator, broadening the vision of the legislators and helping lawmakers in the selection of projects and so on. 


\subsubsection{To Consult the Proposal of Local Legislation from the Public Overtly}

The determination of the legislative project involves the vital interests of all sectors of the community. In order to better balance the interest demand of all walks of life and pursue the social fairness and justice, it is essential to publish the legislative planning and the draft plans and publish in the newspaper or local legislation network to ask for advice on local legislative project from all citizens to continuously improve the openness and transparency of legislation. All social forces need to be aroused to form a benign interactive mechanism, expand the breadth and depth of citizen's participation in legislation and make the legislation more scientific and objective to reflect public opinion. Therefore, we should encourage the free airing of views, draw upon all useful opinions and seriously solicit and adopt the opinions and suggestions of the majority of citizens on local projects. For example, in March 2013, Henan Provincial People's Congress Standing Committee has formulated the compilation formulation of local legislative planning. The compilation of 2014-2018 local legislative plans had been included in the yearly priorities. It consulted the proposal of local legislation from the public overtly, meanwhile, it send letters and notifications for the collection of legislative proposals to members of the Standing Committee, the NPC deputies and the people's organizations, etc. A total of 128 legislative proposals have been received, which makes the legislation more scientific and democratic.

\section{To Strengthen and Deepen the Project Demonstration}

Project demonstration refers to activities that researching on the necessity and feasibility of some legislative proposals to decide whether list it in the program of legislation. Generally, the law working committee, special committees and the government legislative affairs office participate jointly in the project demonstration. We should discuss and argue for reaching a consensus and further put forward the practical and feasible legislation plan under the guidance of a certain legislative technology, taking into consideration both the overall situation of social development, the needs of the people and the connection with central legislation. For several problems covering a wide range or existing great differences, a hearing could be organized to constantly improve the scientific nature of the legislation. The demonstration of legislation project can start with the necessity and possibility of project approval. On this basis, we constantly improve the methods and procedures of legislative planning and legislative programming.

The necessity of the project approval refers to the research activity on the problems that whether the legislation proposed projects are in urgent need for legislation and whether the conditions are ripe, etc. First of all, we should consider whether it conflict with the upper law for ensuring the unification of national legal system, which is the cardinal principle. Although the national legal system is relatively complete and has effectively covered all aspects of social relations, national law has the characteristics of universality, so local legislation can make the abstract principled provisions more concrete. At the same time, the legislation law has clearly defined the legislative jurisdiction between the central and district government. The national legislation does not occupy the space of local legislation. Second, we should consider the specific circumstances and the actual needs of the regions. According to the need reflected by the natural conditions, the cultural environment and the actual social situation of the political and economic development, to make up for the lack of some legal norms which are needed for the supplement and perfect of local legislation. Meanwhile, we must study the status quo of the country's legislation and legislative trends when preparing annual plan and screening legislation project. For example, when some relevant laws and regulations of the country are relatively complete and specific, the regions can not establish projects unless we are not in conformity with the local reality and need to be flexible for execution. And if the country is making a 
legislative plan for certain matters or the relevant laws will be promulgated in the near future, regions should not rush to establish projects to avoid unnecessary waste of legislative resources.

The possibility of project approval refers to the study on whether it is feasible if the proposed project is legislated, which is the forecast of the future operation effect of the regulations. First of all, we should consider the jurisdiction of local legislation. Some matters such as the system of property rights belong to the country's exclusive legislative matters, so local regulations shall not violate the "forbidden area". For the enactment right of administrative licenses, administrative punishment and administrative coercion, etc. state laws define the scope of the jurisdiction of the local laws and regulations. So we should focus on whether the project is beyond the jurisdiction of local regulations when we demonstrate it. Second, we should consider if the main system and measures are legitimate, reasonable and workable. After the publication, some laws and regulations almost have no repercussion in the community, and some can not correctly reflect the social needs and aspirations of the people so the obtained results of them are not good. These are the results of a lack of studies on feasibility. Therefore, we should pay attention to whether there are relevant provisions in the existing laws and regulations from the point of the legislative techniques to avoid the duplication of legislation and consider how to save the cost of legislation. The focus of the work should be transferred from the formulation and revision to the revision and perfection. We need to give priority to the problems with a strong social reflection and achieve that "there are a few then make a few". It is not necessary to pursue the codification mode which is large and all-inclusive. And we should not make the legislative form cumbersome. We shall try to guide the legislation with problems, value "fewer but better", work hard on key clause and consider the use of legislative style with simple model such as "certain regulations". Local legislation also must be certain forward-looking and predictive. If we always follow in social footsteps, the inflexible regulations lack of mobility and flexibility will be the result. We should avoid the tendency of chasing the departmental interests and prevent the interests of the sector over the public interest. The content of laws and regulations must be legal, reasonable, clear and specific. We should not turn out to be a mere formality. And we must able to carry out and implement in society.

\section{CONClusion}

In the masterpiece of improving the socialist legal system with Chinese characteristics, local people's Congress and its standing committee are responsible for the important mission, and local legislation has a broad space for development. Because the legal system of socialism with Chinese characteristics is a large and complex system and standard system, local legislation, as an integral part of the whole harmonious unity, is an indispensable important link in the complete system, which plays a unique role of nexus. Our country has a vast territory. The economic and social development is unbalanced among various regions. And the development is rapid. The problem exists in every area to implement any laws and policies approved by the state, which requires the local place timely formulate regulations for implementation to safeguard. Years of practice has proved that it is not good to centralize the legislative authority in the national centre. That is not conducive to the development of every undertaking and the promotion of the rule of law. Local legislation should adapt to local circumstances and make provisions in a targeted manner. It can flexibly apply the laws, regulations and policies, not rigidly adhere to the specific style, specification and form. Especially in the economic, administrative, social and other fields, the space and scope of local legislation is very large. In every developing period of our country in the future, all kinds of local affairs will appear, which needs local people's Congress and its standing committee target on the local specific issues, collect and integrate relevant laws, administrative regulations and policies and timely formulate relevant laws 
and regulations to solve specific issues of these places. With the development of society and economy, the new local problems are arising while the new solutions will be coming out. National legislation is always relatively hysteretic, which needs local legislation to "prior to carry and try".

\section{ACKNOWLEDGEMENTS}

Jingzhou science and technology development project (2015AD52);

Legislative Research Project of Jingzhou People's Congress Standing Committee (15JZLF02);

Youth Foundation of Yangtze University (2015cqn01);

Society Science Foundation of Yangtze University (2015csy009);

Innovation Foundation of Social Assistance Research Center of Yangtze University (15JZ03).

\section{REFERENCES}

[1] Jiao Hongchang, Ma Xiao. The expansion of local legislative power and modernization of national governance [J]. Journal of the party school of CPC central committee, 2014, 5.

[2] Qin Qianhong, Li Shaowen. The countermeasure for the expansion of local legislative power [J]. The science of law, 2015, 7.

[3] Yan Pengtao. Discussion on mechanism model of the project demonstration of regulations from local people's congress [J]. People's congress studying, 2011, 7.

[4] Qian Zhao, Xiaoping Wang. The Analysis of statistics legislative value in China [J]. Canadian social science, $2015,4$.

[5] Jing-bo Zhao. Harmonious society and the changes in concepts of local legislation [J]. Canadian social science, 2010, 3 .

[6] Qian Zhao. A thought of taking CPPCC as Chinese professional supervisory institution of unconstitutional behavior in applying law [J]. Canadian social science, 2011, 3. 